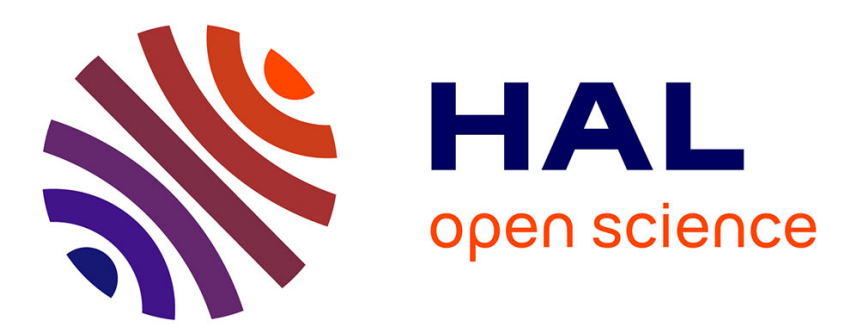

\title{
Influence of parasitic resistances on the mismatch relative power loss of solar cell modules
}

\author{
P.H. Nguyen, T. Easwarakhanthan, S. Ravelet
}

\section{To cite this version:}

P.H. Nguyen, T. Easwarakhanthan, S. Ravelet. Influence of parasitic resistances on the mismatch relative power loss of solar cell modules. Revue de Physique Appliquée, 1985, 20 (10), pp.689-693. 10.1051/rphysap:019850020010068900 . jpa-00245384

\section{HAL Id: jpa-00245384 https://hal.science/jpa-00245384}

Submitted on 1 Jan 1985

HAL is a multi-disciplinary open access archive for the deposit and dissemination of scientific research documents, whether they are published or not. The documents may come from teaching and research institutions in France or abroad, or from public or private research centers.
L'archive ouverte pluridisciplinaire HAL, est destinée au dépôt et à la diffusion de documents scientifiques de niveau recherche, publiés ou non, émanant des établissements d'enseignement et de recherche français ou étrangers, des laboratoires publics ou privés. 


\title{
Influence of parasitic resistances on the mismatch relative power loss of solar cell modules
}

\author{
P. H. Nguyen (*), T. Easwarakhanthan and S. Ravelet \\ Institut des Sciences de l'Ingénieur, Laboratoire d'Electronique et de Physique des Interfaces, \\ Parc Robert Bentz, 54500 Vandoeuvre-lès-Nancy, France \\ (*) Laboratoire d'Applications de la Microélectronique, Faculté des Sciences de Reims, Moulin de la Housse, \\ BP 347, 51062 Reims Cedex, France
}

(Reçu le 26 avril 1984, révisé le 18 juin 1985, accepté le 27 juin 1985)

\begin{abstract}
Résumé. - La puissance crête fournie par un module photovoltaïque est réduite par la dispersion des valeurs des courants photogénérés des cellules, ceci est dû essentiellement aux procédés de fabrication. Pour améliorer la puissance de sortie, les cellules sont triées en vue de réduire cette dispersion avant d'être placées en série pour former un module. Une analyse assistée par calculateur a été effectuée pour étudier la perte relative de puissance due à la dispersion (mmRPL) et, en particulier, l'influence de la conductance shunt parasite. Une expression empirique et une méthode simple d'évaluation du facteur de perte mmRPL sont proposées pour un module connecté en série et, dans une certaine mesure, ces résultats sont étendus aux panneaux constitués de cellules mises en parallèle.
\end{abstract}

\begin{abstract}
Peak power available from a photovoltaic module is reduced by the cell-to-cell variations in the photogenerated current, which originate from the manufacturing process. In order to enhance the array output power, the cells are generally sorted before being placed in modules. A computer analysis performed allows to assess the mismatch relative power loss (mmRPL), particularly the influence of the parasitic shunt conductance. Empirical expressions and a method of evaluation are proposed for the mmRPL of a series-connected module and, to a limited extent, for mmRPL of a parallel-connected module.
\end{abstract}

\section{Introduction.}

Loss of output power from a solar cell module is unavoidable due to (i) the manufacturing deficiencies (dispersion in the characteristics of cells, presence of non negligible parasitic resistances) and (ii) the incorporation of the integrated bypass diode in the unit cell structure.

Previous studies on the performance of photovoltaic solar arrays under dispersive conditions have concentrated upon a statistical approach to the problem both from a mathematical point of view [1-3] and numerical simulations [4-6]. Except the Bucciareli's analysis which has taken into account only two stochastic parameters i.e. the current and voltage at the max-power point, these papers have used the common assumption : for " carrefully designed " cells, the shunt resistance is generally disregarded or assigned a typical high value. In order to resolve the hot spot problem i.e. the presence of localized overheating resulting from a partial or total shadowing of some cells in the module, in contrast, many authors [7-10] have suggested the incorporation of bypass diodes or relatively high shunt conductance in the solar cell design. In fact, it is well-known that the dispersion in the values of photogenerated current can be assimilated to a partial shadowing of different cells in a series connected module and the " relatively " high value of shunt conductance can then reduce both the hot spot problem and the mismatch effect. In order to reduce the latter, Lambarski et al. [11] have proposed a sorting method of the photovoltaic cells and modules in a array into four bins according to a Gaussian distribution.

The purpose of this paper is to investigate the influence of parasitic resistances on the efficiency of a conventional solar module without bypass diodes by numerical approaches. The solar cell parameters are treated as independent stochastic variables and are divided into two groups : (i) intrinsic parameters, the photogenerated current $I_{\mathrm{L}}$, the factor $B(=q / n k T)$ and the saturation current $I_{\mathrm{s}}$, (ii) parasitic resistances, 
the series resistance $R_{\mathrm{s}}$ and the shunt resistance $1 / G_{\mathrm{sh}}$. Most of the results presented are for series-connected arrays. Important conclusions are made concerning different effects on the module performance.

\section{Numerical simulation.}

The current-voltage characteristics of a solar cell is generally represented with a good accuracy in its working range, by a double-exponential relationship of the following form :

$$
\begin{array}{r}
I=I_{\mathrm{L}}-\sum_{j=1}^{2} I_{\mathrm{s} j}\left[\exp \left\{B_{j}\left(V+R_{\mathrm{s}} I\right)\right\}-1\right]- \\
-G_{\mathrm{sh}}\left(V+R_{\mathrm{s}} I\right) .
\end{array}
$$

Assuming a baseline panel with identical solar cells in $N_{\mathrm{p}}$ parallel branches each comprised of $N_{\mathrm{s}}$ cells in series, the two exponential $I-V$ characteristic of the solar panel can be easily deduced by scaling the current and voltage $\left(I_{\mathrm{p}}=N_{\mathrm{p}} I, V_{\mathrm{p}}=N_{\mathrm{s}} V\right)$ with :

$$
\begin{gathered}
I_{\mathrm{Lp}}=N_{\mathrm{p}} \bar{I}_{\mathrm{L}} \quad I_{\mathrm{sp} j}=N_{\mathrm{p}} \bar{I}_{\mathrm{s} j} \quad B_{\mathrm{p} j}=\bar{B}_{j} / N_{\mathrm{s}} \\
R_{\mathrm{sp}}=\bar{R}_{\mathrm{s}} N_{\mathrm{s}} / N_{\mathrm{p}} \quad G_{\mathrm{sp}}=\bar{G}_{\mathrm{sh}} N_{\mathrm{p}} / N_{\mathrm{s}}
\end{gathered}
$$

where the subscript $\mathrm{p}$ stands for the specified seriesparallel connected panel, $\bar{B}_{j}^{-1}=\bar{n}_{j} k T / q$ the average thermal voltage and the notation «-» corresponds to a mean identical sample (MIS). The other parameters have their usual meanings. It is also well-known that the efficiency and the fill factor remain unchanged :

$$
\eta_{\mathrm{p}}=\bar{\eta} \text { and } f_{\mathrm{p}}=\bar{f} \text {. }
$$

The mean relative power loss can be defined by :

$$
\text { MRPL }=100\left\{\left(\bar{\eta}_{0}-\bar{\eta}\right) / \bar{\eta}_{0}\right\}
$$

where the subscript 0 stands for the ideal case $\left(R_{\mathrm{s}}=0\right.$, $G_{\text {sh }}=0$ ).

For a module with non identical cells the mismatch relative power loss (mmRPL) is defined by :

$$
\operatorname{mmRPL}=100\left\{\left(\bar{\eta}-\eta_{\mathrm{p}}\right) \sqrt{\eta}\right\}
$$

where $\eta_{p}$ is the efficiency of the real module and $\bar{\eta}$ is the efficiency if the module is considered as an assembly of mean identical samples. The total relative power loss (TRPL) is now defined by :

$$
\text { TRPL }=100\left\{\left(\bar{\eta}_{0}-\eta_{\mathrm{p}}\right) \bar{\eta}_{0}\right\}
$$

It is obvious that from these definitions the overestimated value of TRPL is

$$
\text { TRPL } \leqq M R P L+m m R P L .
$$

By substituting the denominator of equation (5) by $\bar{\eta}_{0}$ the TRPL is the sum of MRPL and mmRPL. In fact, the definition of equation (5) is more commonly used in the literature.
In order to estimate these two loss mechanisms by numerical computations, the method of approach is adopted as follows.

It has been shown using a published program package written in Fortran and Basic language for generating and characterizing $I-V$ curves [12] that the two exponential current-voltage characteristics can be adequately approached by a single-exponential model in its working range and particularly about the maximum power point :

$I=I_{\mathrm{L}}-I_{\mathrm{s}}\left[\exp \left\{B\left(V+R_{\mathrm{s}} I\right)\right\}-1\right]-G_{\mathrm{sh}}\left(V+R_{\mathrm{s}} I\right)$

where $I_{\mathrm{s}}$ is the " equivalent " saturation current $\left(I_{\mathrm{s} 1}<I_{\mathrm{s}}<I_{\mathrm{s} 2}\right), B$ is such that $B_{2}<B<B_{1}$ and the new values of parasitic resistances $R_{\mathrm{s}}$ and $R_{\mathrm{sh}}$ are the under-estimated ones.

Thus, without loss of generalities and for simplicity, the characteristics $I_{\mathrm{p}}-V_{\mathrm{p}}$ of series-connected modules of 34 cells (about 30 theoretical data points) are generated on the basis of a single-diode model. The parameters, the sum of the powers of individual cells, the module short circuit current, the module maximum power point and the module open circuit voltage are also computed to deduce mmRPL, $f_{\mathrm{p}}$ and $\eta_{\mathrm{p}}$. The program is carried out in Basic on CBM microcomputer.

For each module, 170 parameters, five for each cell, are generated. This is accomplished by the random number generation instruction associated with the central limit theorem. Next, the parameters are checked to ensure that they exhibit a normal distribution.

Table I lists the module parameters, their mean value, relative standard deviation. The relative standard deviation (RSD) for the MIS open circuit voltage can be monitored $(\cong \sigma(B))$ if the RSD of the natural logarithm of the saturation current is less than $\sigma(B) / 2$. For each typical module (MOD $k$ ), two modules (MOD 0.k) and (MOD k.0) are also generated, the first one by assigning respectively the intrinsic parameters to their mean values (identical values) and the parasitic resistances to their generated values and the latter by assigning respectively the intrinsic parameters to their generated values and the parasitic parameters $R_{\mathrm{s}}$ and $G_{\mathrm{sh}}$ to zero.

\section{Results and discussion.}

Table II lists the main results : the MIS efficiency and fill factor, the module efficiency, module fill factor and the different RPL components. The results for MIS have been obtained from the SOLEF2 program [12] with a relative accuracy of $10^{-8}$ and those for simulated modules (MOD) are deduced from the actual program with a relative accuracy of $10^{-5}$. Since the numerical computations are not identical, the values of the efficiency and the fill factor of MIS $j$ and MOD $j$ present a weak discrepancy i.e. the fill factor and the efficiency of the mean identical sample 
Table I. - Module parameters, their mean value and RSD.

\begin{tabular}{|c|c|c|c|c|c|c|c|c|c|c|}
\hline Module & $\begin{array}{l}n \\
(T=300 \mathrm{~K})\end{array}$ & $\begin{array}{l}\sigma \\
\%\end{array}$ & $\begin{array}{l}I_{\mathrm{s}} \\
\mathrm{A}\end{array}$ & $\begin{array}{c}\sigma \\
{\left[\operatorname{Ln}\left(I_{\mathrm{s}}\right)\right] \%}\end{array}$ & $\begin{array}{l}I_{\mathrm{L}} \\
\mathrm{A}\end{array}$ & $\begin{array}{c}\sigma \\
\%\end{array}$ & $\begin{array}{l}R_{\mathrm{s}} \\
\boldsymbol{\Omega}\end{array}$ & $\begin{array}{l}\sigma \\
\%\end{array}$ & $\begin{array}{l}G_{\text {sh }} \\
\Omega^{-1}\end{array}$ & $\begin{array}{l}\sigma \\
\%\end{array}$ \\
\hline MOD 1 & 1.51 & 10 & $5.6 \times 10^{-8}$ & 2.0 & 1.07 & 26 & 0.204 & 20 & 0.02 & 16 \\
\hline MOD 2 & 1.37 & 9.0 & $9.7 \times 10^{-8}$ & 5.0 & 2.255 & 12 & 0.0203 & 33 & 0.0205 & 36 \\
\hline MOD 0.2 & 1.37 & 0 & $9.7 \times 10^{-8}$ & 0.0 & 2.255 & 0 & 0.0203 & 33 & 0.0205 & 36 \\
\hline MOD 2.0 & 1.37 & 9.0 & $9.7 \times 10^{-8}$ & 5.0 & 2.255 & 12 & 0 & - & 0 & - \\
\hline MOD 3 & 1.4 & 5 & $1.04 \times 10^{-7}$ & 2 & 2.257 & 11 & 0.029 & 24 & 0.389 & 24 \\
\hline MOD 0.3 & 1.4 & 0 & $1.04 \times 10^{-7}$ & 0 & 2.257 & 0 & 0.029 & 24 & 0.389 & 24 \\
\hline MOD 3.0 & 1.4 & 5 & $1.04 \times 10^{-7}$ & 2 & 2.257 & 11 & 0.0 & - & 0. & - \\
\hline MOD 4 & 1.395 & 6 & $4.04 \times 10^{-8}$ & 4 & 2.236 & 6 & 0.02 & 5.0 & 0.2005 & 5.0 \\
\hline MOD 0.4 & 1.395 & 0.0 & $4.04 \times 10^{-8}$ & 0.0 & 2.236 & 0.0 & 0.02 & 5.0 & 0.2005 & 5.0 \\
\hline MOD 4.0 & 1.395 & 6 & $4.04 \times 10^{-8}$ & 4 & 2.236 & 6 & 0 & - & 0 & - \\
\hline MOD 5 & 1.395 & 6 & $1.0 \times 10^{-7}$ & 4 & 2.257 & 11 & 0.0102 & 41 & 0.039 & 40 \\
\hline
\end{tabular}

Table II.-Main results : efficiency, fill factor and different RPL.

\begin{tabular}{lccccccc}
\multicolumn{1}{r}{ Result } & $\begin{array}{c}\bar{\eta} \\
\%\end{array}$ & $\begin{array}{c}\bar{f} \\
\%\end{array}$ & $\begin{array}{c}\eta_{\mathrm{p}} \\
\%\end{array}$ & $\begin{array}{c}f_{\mathrm{p}} \\
\%\end{array}$ & $\begin{array}{c}\text { mmRPL } \\
\%\end{array}$ & $\begin{array}{c}\text { MRPL } \\
\%\end{array}$ & $\begin{array}{c}\text { TRPL } \\
\%\end{array}$ \\
\hline MIS 1.0 & 16.24 & 80.14 & 16.24 & 80.14 & 0 & 0 & 0 \\
MIS 1 & 11.15 & 55.29 & 11.15 & 55.29 & 0 & 31.3 & 31.3 \\
MOD 1 & 10.88 & 55.12 & 7.53 & 60.79 & 30.8 & 33.0 & 53.6 \\
\hline MIS 2.0 & 13.53 & 78.43 & 13.53 & 78.43 & 0 & 0 & 0 \\
MIS 2 & 12.34 & 71.59 & 12.34 & 71.59 & 0 & 8.8 & 8.8 \\
MOD 2.0 & 13.57 & 78.40 & 11.04 & 91.64 & 18.6 & 0 & 18.6 \\
MOD 0.2 & 12.343 & 71.62 & 12.341 & 71.60 & 0.012 & 8.8 & 9.1 \\
MOD 2 & 12.35 & 71.56 & 10.36 & 76.57 & 16.1 & 8.7 & 23.4 \\
\hline MIS 3.0 & 13.77 & 78.37 & 13.77 & 78.37 & 0 & 0 & 0 \\
MIS 3 & 11.12 & 64.42 & 11.12 & 64.42 & 0 & 19.2 & 19.2 \\
MOD 3.0 & 13.79 & 78.36 & 12.66 & 88.17 & 8.2 & 0 & 8.2 \\
MOD 0.3 & 11.12 & 64.38 & 11.09 & 64.27 & 0.27 & 19.2 & 19.5 \\
MOD 3 & 11.13 & 64.29 & 10.37 & 61.64 & 6.8 & 19.2 & 24.7 \\
\hline MIS 4.0 & 14.49 & 79.17 & 14.49 & 79.17 & 0 & 0 & 0 \\
MIS 4 & 12.73 & 70.05 & 12.73 & 70.05 & 0 & 12.2 & 12.2 \\
MOD 4.0 & 14.56 & 79.15 & 14.12 & 86.16 & 3.0 & 0 & 3.0 \\
MOD 0.4 & 12.732 & 70.03 & 12.731 & 70.05 & 0.008 & 12.1 & 12.2 \\
MOD 4 & 12.79 & 70.02 & 12.49 & 69.43 & 2.3 & 11.7 & 13.8 \\
\hline MIS 5.0 & 13.76 & 78.40 & 13.76 & 78.40 & 0 & 0 & 0 \\
MIS 5 & 13.06 & 74.50 & 13.06 & 74.50 & 0 & 5.1 & 5.1 \\
MOD 5 & 13.08 & 74.47 & 12.06 & 76.74 & 7.8 & 4.9 & 12.4 \\
\hline
\end{tabular}

of a module are not exactly equal to the mean fill factor and the mean efficiency of individual cells of the same module. Indeed, for the worst case 1 (badly sorted and not well-designed cells) these discrepancies are less than $3 \%$. The mean values of MOD 1 are in the same order of the mean values of 100-cell array in a previous study [6] except that for the shunt conductance. According to our previous work [13], the contribution of the normalized conductance to the MRPL is negligible, thus the power loss due to 
parasitic resistances is ascribed, in this case, essentially to the mean series resistance of about $0.2 \Omega$.

In contrast, for a well-sorted module MOD 4 the mmRPL is reduced to about $3 \%$. It is well known that the main contribution to mismatch relative power loss comes either from the variation of the short circuit current of each individual cell about a mean value [2] or the relative dispersion of the max-point current of each cell [3]. In fact, it is found from our simulated modules that these relative dispersions are in the same order of values and can be estimated by the relative dispersion of the photogenerated current $I_{L}$. The manufacturers generally specify a tolerance of 10 or $12.5 \%$. By assuming a normal distribution, the relative dispersion of $I_{\mathrm{L}}$ is found to be about a half of this tolerance (i.e. 5 or $6 \%$ ).

In the opposite case, for a well designed (i.e. with « negligible » parasitic resistances) series-connected module MOD 5 the MRPL is about $5 \%$. Finally, MOD 2 and MOD 3 correspond respectively to the intermediate cases of a standard sorted module and not well designed series-connected cells. As a first remark, the TRPL of a well-sorted and well-designed series-connected module can be kept less than 6 or $7 \%$ in the best cases.

A second significant conclusion that can be made from these results deals with the influence of parasitic resistances on the mmRPL : (i) their own contribution, as a result of dispersion in the values of parasitic resistances, to $\mathrm{mmRPL}$ can be disregarded for practical solar modules (mmRPL of MOD $0 . \mathrm{j}<0.5 \%$ ) according to a previous work [11], (ii) the increase of the mean shunt conductance can give rise to a corresponding increase in the module short circuit current and, as a consequence, a decrease in mmRPL $(\operatorname{mmRPL}[\mathrm{MOD} j]<\operatorname{mmRPL}[\mathrm{MOD} j .0])$ but, which cause also an increase of the total relative power loss. In fact, the weakest cell should now be defined by the cell with the minimum value of $\left(I_{\mathrm{L}}-G_{\mathrm{sh}} V_{\mathrm{sc}}\right)=$ $I_{\mathrm{scm}}$ where $V_{\mathrm{sc}}$ is the reverse bias $\left(V_{\mathrm{sc}}<0\right)$ voltage of this cell under the short circuit conditions and $I_{\text {scm }}$ is the module short circuit current, (iii) defining the module curve fill factor in the conventional form, i.e.

$$
f_{\mathrm{p}}=\left(\eta_{\mathrm{p}} P_{\mathrm{i}}\right) /\left(I_{\mathrm{scm}} V_{\mathrm{ocm}}\right)
$$

where $P_{\mathrm{i}}$ is the incident power, $V_{\text {ocm }}$ the module open circuit voltage which is practically unaffected by the mismatch effect in the series-connected configuration leads to a square-like $I-V$ characteristic only when there is a large dispersion in the photogenerated current associated with a relatively low shunt conductance. The relative variation $\left(\bar{f}-f_{\mathrm{p}}\right) / \bar{f}$ is thus negative according to the previous analysis $[4,6]$. In contrast, for a higher shunt conductance, the degradation of the $I-V$ curve occurs and this variation can become positive.

As a result of these conclusions, an empirical expression for the mmRPL can be obtained :

$$
\operatorname{mmRPL}=\left(\bar{I}_{\mathrm{sc}}-I_{\mathrm{scm}}\right) / \bar{I}_{\mathrm{sc}}+\left(\bar{f}-f_{\mathrm{p}}\right) / \bar{f}
$$

where $\bar{I}_{\text {sc }}$ is the MIS short circuit current and is approached by the mean value of short circuit currents of individual cells. Table III gives comparative estimations of mmRPL for the simulated modules. According to the Bucciarelli's analysis for a seriesconnected module, the relative dispersion of maxpoint current and the factor $c$ [3] are also computed to deduce the estimation. According to the Luque's analysis, the mmRPL of a 34 cells in series is given by :

$$
\mathrm{mmRPL} \cong 1.8 \sigma\left(I_{\mathrm{sc}}\right) / \bar{I}_{\mathrm{sc}}
$$

where $\sigma\left(I_{\mathrm{sc}}\right) / \bar{I}_{\mathrm{sc}}$ is the relative standard deviation of the short circuit current and equal to the relative dispersion of the photogenerated current for practical modules. The Luque's values have obviously an upper bound [2] for the mmRPL since the shunt conductance is neglected and the fill factor is taken as a constant, while the Bucciarelli's results have generally a lower bound. As a characteristic feature, the mmRPL deduced from equation (10) gives satisfactory estimamations particularly for high values $(>10 \%)$ and the measurement method is quite simple. The manufacturer can measure (i) the mean values $\bar{I}_{\text {sc }}$ and $\bar{f}$ for $N$ individual cells $(N>30$ for example), (ii) then, the module short circuit current $I_{\mathrm{scm}}$ and the module curve factor $f_{\mathfrak{p}}$ under the same operating conditions (i.e. for the temperature and the illumination) to deduce a good estimation of $\mathrm{mmRPL}$ from equation (10).

To a limited extent, parallel-connected arrays can be investigated. According to the present results and the previous analysis $[2,3]$, an empirical expression of mmRPL for parallel-connected cells could be proposed

$$
\operatorname{mmRPL}=\left(\bar{V}_{\mathrm{oc}}-\bar{V}_{\mathrm{ocm}}\right) / \bar{V}_{\mathrm{oc}}+\left(\bar{f}-f_{\mathrm{p}}\right) / \bar{f}
$$

where $\bar{V}_{\mathrm{oc}}$ is the mean value of the open circuit voltage of individual cells and $V_{\text {ocm }}$ the parallel-connected module open circuit voltage. Further simulations will be investigated to check the validity of this empirical expression. It is also of interest to determine the second loss component MRPL since the mean relative power

Table III.- Different estimations of mmRPL.

\begin{tabular}{lcccc} 
Module & $\begin{array}{c}\text { Exact } \\
\text { value } \\
\%\end{array}$ & $\begin{array}{c}\text { Bucciarelli } \\
{[3]} \\
\%\end{array}$ & $\begin{array}{c}\text { from } \\
\text { Luque } \text { et al. [2] } \\
\%\end{array}$ & $\begin{array}{c}\text { from } \\
\text { equation (10) } \\
\%\end{array}$ \\
\hline MOD 1 & 30.8 & 15.6 & $<47.6$ & 28.1 \\
MOD 2.0 & 18.6 & 10.5 & $<20.6$ & 13.3 \\
MOD 2 & 16.1 & 7.0 & $<20.6$ & 14.5 \\
MOD 3.0 & 8.2 & 9.9 & $<20.2$ & 5.7 \\
MOD 3 & 6.8 & 5.9 & $<20.2$ & 7.9 \\
MOD 4.0 & 3.0 & 2.8 & $<10.4$ & 1.7 \\
MOD 4 & 2.3 & 1.65 & $<10.4$ & 2.4 \\
MOD 5 & 7.8 & 8.0 & $<20.2$ & 7.3 \\
\hline
\end{tabular}


loss cannot be neglected for practical series-connected modules (i.e. combinations of MOD 4 and MOD 5).

As for practical applications, the behaviour of a large solar cell consisting of smaller unit cells in parallel has been investigated by Jacquemin and Bordure [14]. According to their experimental measurements and numerical simulation, the equation (12) can be checked in the case mmRPL $\cong 0$ since $V_{\text {ocm }}$ and $f_{\mathrm{p}}$ are nearly the same as those obtained with their 30 simulated identical cells in parallel. This fact may be explained by the compromise between the average normalized series resistance $r=9 \%$ [13] and the lowest open circuit voltages which can be estimated from the normalized standard deviations $\sigma\left(V_{\mathrm{oc}}\right) / \bar{V}_{\mathrm{oc}}=$ $7 \%$. In fact, if the series resistances losses in a parallel array are reduced but the scatter in the $V_{\text {oc }}$ values is relatively important, the $\mathrm{mmRPL}$ cannot be discarded according to a previous analysis [2]. The second loss component MRPL of their 30 real $\mathrm{Cu}_{2} \mathrm{~S}-\mathrm{CdS}$ solar cells is then the major loss in this case and its value is evaluated to be about $14 \%$ according to a previously proposed semiempirical expression [13].

\section{Conclusion.}

The intent of this analysis was to obtain an indication of the approximate power losses due to photogenerated current variations and to show that improvements in mmRPL of the series-connected solar cell modules as a result of cell matching (i.e. the compromise between the values of the lowest photogenerated currents and the normalized shunt conductances about 2-3\%) can occur in well-sorted modules. As a consequence, the hot spot effect can also be reduced but, in counter part, the total relative power loss $(\cong \mathrm{mmRPL}+$ MRPL) increases in the same amount.

\section{Acknowledgments.}

The authors wish to thank L. Bouhouch for help in this work.

\section{References}

[1] Bany, J., Appelbaum, J. and Braunstein, A., IEEE Trans. Electron Dev., ED-24 (1977) 1032.

[2] LuQue, A. and Lorenzo, E., Sol. Energy 22 (1978) 187. Luque, A., Lorenzo, E. and Ruiz, J. M., Proc. of the I.S.E.S. Congress (1979) 1851.

[3] Bucciarelli, Jr. L. L., Sol. Energy 23 (1979) 277.

[4] Watkins, J. L. and Burgess, E. L., Proc. of the 12th IEEE Photovoltaic Specialist Conference (1978) 1061 .

[5] Roger, J. A. and Maguin, C., Sol. Energy 29 (1982) 245.

[6] Shechter, M., Appelbaum, J. and Yekutieli, G., Sol. Cells 9 (1983) 295.

[7] Swaleh, M. S. and Green, M. A., Sol. Cell 5 (1982) 183.

[8] Sirito, P. and Alvergamo, V., Proc. of the 4th E.C. Photovoltaic Solar Energy Conference, STRESA (1982) 296.
[9] Roger, J. A., Massaad, S., Posbic, J. and Pivot, J., Proc. of the 4th E.C. Photovoltaic Solar Energy Conference, STRESA (1982) 301.

[10] LAMBarsKi, T. J., ANDERSON, E. R. and Rogers, C. B., Proc. of the 16th IEEE Photovoltaic Specialist Conference (1982) 1020.

[11] Lambarski, T. J., KaDleC, D. L. and Rogers, C. B., Proc. of the 15th Photovoltaic Specialist Conference (1981) 841.

[12] Nguyen, P. H., Thèse de Doctorat d'état, Université de Nancy 1 (1984).

[13] NguYen, P. H. and Ravelet, S., Proc. of the 5th E.C. Photovoltaic Solar Energy Conference (D. Reidel Publ. Comp.) 1983, p. 124.

[14] JACQuemin, J. L. and Bordure, G., Sol. Cells 5 (1982) 269. 